\title{
Care and Support Programmes for Orphans and Vulnerable Children: Achievements and Implications of HIV/AIDS Funded Project in Osun State, Nigeria
}

\author{
Adebola A. Adejimi1,2*, Ajibola Olagunoye1 ${ }^{1}$, Adeyemi Amuda', Olubukola Alawale ${ }^{1}$, \\ Oluwatoyin Adeola-Musa',3, Abayomi Adenekan', Akin Oyebade ${ }^{4}$, Mosur Bello", \\ Michael Olugbile5, Olusegun Adeoye5, Gabriel Olatunji ${ }^{4}$
}

\author{
${ }^{1}$ Department of Community Medicine, Ladoke Akintola University of Technology (LAUTECH) Teaching Hospital, Osogbo, \\ Osun State, Nigeria \\ ${ }^{2}$ Department of Community Medicine, University of Ibadan, Ibadan, Nigeria \\ ${ }^{3}$ Department of Epidemiology and Disease Control, Osun State Ministry of Health, Osogbo, Osun State, Nigeria \\ ${ }^{4}$ Osun State Agency for the Control of AIDS, Osogbo, Nigeria \\ ${ }^{5}$ HIV Programme Development Project (HPDP2), World Bank, Abuja, Nigeria \\ Email: *adebolaa dejimi@yahoo.com
}

How to cite this paper: Adejimi, A.A., Olagunoye, A., Amuda, A., Alawale, O., AdeolaMusa, O., Adenekan, A., Oyebade, A., Bello, M., Olugbile, M., Adeoye, O. and Olatunji, G. (2019) Care and Support Programmes for Orphans and Vulnerable Children: Achievements and Implications of HIV/AIDS Funded Project in Osun State, Nigeria. World Journal of AIDS, 9, 195-213.

https://doi.org/10.4236/wja.2019.94015

Received: June 21, 2019

Accepted: December 28, 2019

Published: December 31, 2019

Copyright $\odot 2019$ by author(s) and Scientific Research Publishing Inc. This work is licensed under the Creative Commons Attribution International License (CC BY 4.0).

http://creativecommons.org/licenses/by/4.0/

cc) (i) Open Access

\begin{abstract}
Orphans and Vulnerable Children (OVC) and their families face many challenges but there are opportunities to provide care and support programmes for them in their communities. This paper presents the achievements and implications of HIV Programme Development Project (HPDP) funded by World Bank on care and support services for OVC in Osun State, Nigeria. Eight Civil Society Organisations (CSOs) were engaged by Osun State Agency for the Control of AIDS (OSACA) as part of HPDP to provide care and support services for OVC between year 2013 and 2015. Using reporting tools, data collected by the CSOs were entered into District Health Information System 2 (DHIS2) platform and analysed using Microsoft Excel. In addition, Key Informant Interviews (KII) were conducted among the selected CSOs, OVC and the caregivers who were beneficiaries of HPDP in Osun State, Nigeria. A total of 12,353 OVC were reached and about half of them were female. There was an increase in the trends of number of OVC seen and the support services provided from the year 2013 to 2015 . Of the 12,353 OVC that benefitted from this programme, $1905(15.4 \%)$ received health care services, 5383 (43.6\%) received nutritional services, $5317(43.0 \%)$ received educational services and 9861 (79.8\%) were provided with psychosocial support services. About 503 (4.1\%) of the OVC received economic strengthening services while 270 (2.2\%) of household heads were provided with economic support. However, 3 OVC
\end{abstract}


were lost to follow-up, 14 OVC voluntarily withdrew from the project and 6 OVC died. The FGD and KII revealed that the project was very impactful in transforming the lives of the OVC. Programmes for children orphaned and made vulnerable by HIV/AIDS will contribute to the achievement of HIV/ AIDS prevention and control efforts. The HIV/AIDS free generation can be built by responding to the physical, social and mental needs of these children and their families in their communities. There is a need to scale-up this programme.

\section{Keywords}

HIV, Orphans, Vulnerable Children, HPDP, Care and Support, Nigeria

\section{Introduction}

The Human Immunodeficiency Virus/Acquired Immune Deficiency Syndrome (HIV/AIDS) pandemic has impacted children in many ways; from parental loss, to HIV infection, to increased poverty and marginalization, and these children have been labelled Orphans and Vulnerable Children (OVC). The World Bank defines OVC as children who are orphaned, separated from their parents, living with caregivers with serious problems like illness, disabilities, trauma, substance addictions, abusive habits, or having normal families, but with special needs such as trauma, disability and behavioural problems that even well-functioning parents will need help to address [1]. United Nations Programme on HIV/AIDS (UNAIDS) defines OVC as orphans and children less than 18 years of age whose mother, father, or both parents have died as a result of AIDS [2]. The United States President's Emergency Plan for AIDS Relief (PEPFAR) defines OVC as children ages 0 - 17, who are either orphaned or made more vulnerable because of HIV and AIDS [3].

The United Nations Children Funds (UNICEF) estimates that the number of orphans (age 0 - 17 years) globally is 140 million, with an estimated 17.7 million orphans attributed to AIDS [4]. In sub-Saharan Africa (SSA) there are close to 60 million orphans, a number that represents more than $20 \%$ of all children in this region. An estimated 15.2 million children in SSA are orphaned due to AIDS [4]; this represents $86 \%$ of the global burden of orphans due to AIDS. There is a huge and growing number of OVC in Africa due to the high proportion of adults in the region living with HIV/AIDS. The population of orphan in Nigeria is estimated to be $20 \%$ of the total SSA orphan population [5]. Although official counts vary, the Federal Ministry of Women Affairs and Social Development in Nigeria reported that there were 17.5 million OVC in 2008 [6]. UNICEF reported 10 million Nigerian orphans due to all causes in 2013, with 2.3 million orphans due to AIDS, as well as 450,000 children and 180,000 adolescents actually living with HIV [4]. One in every 10 households in Nigeria is estimated to be providing care for an orphan [7]. 
The scourge of HIV/AIDS has negatively impacted the development of communities affected by it, as it continues to devastate individuals, families and households, affecting their physical, social, psychological and economic wellbeing. Parental death can affect a growing child's development; it can result in loss of shelter, school drop-out or non-enrolment in school, physical and psychological abuse, lack of access to health, poor health outcomes, malnutrition, poverty, stigmatization, lack of love and affection and negative communities' attitude towards them [6] [8]. School enrolment status of OVC in Africa depends on households' resources and the public support for education [9]. When a parent dies, older children may be expected to take up paid employment and care for the younger siblings. Loss of parent(s) can affect the child's development, older children may experience sexual and economic exploitation and at higher risk of sexually transmitted diseases [10]. Because of these, OVC require urgent basic needs, services and supports that can be provided to them within their communities.

The World Bank supported HIV response in Nigeria through the first HIV/ AIDS Programme Development Project which ended in March 2010 and the second HIV/AIDS Programme Development Project (HPDP 2) which commenced in the year 2011. The HIV/AIDS Programme Development Project II (HPDP 2) was a 5-year Word Bank and State counterpart funded project aimed at reducing the risk of HIV infections by scaling up prevention interventions as well as by increasing access to and utilization of HIV counselling, testing, care and support services. HPDP 2 implementation was by the National Agency for the Control of AIDS through the State Agencies for the Control of AIDS which coordinated the stakeholders at different levels such as the Government ministries, non-governmental organizations and private sector. The HPDP 2 had three components which included-expanding the public sector response, expanding the civil and private sector engagement and response, and strengthening mechanism for project coordination and management.

Osun State Agency for the Control of AIDS (OSACA) recognizes the importance of meeting the needs of these children, orphaned or made vulnerable by HIV/AIDS as the State is committed to ensuring sound and good health of its people. With support from World Bank and evidence-based policies, care and support programme of these children was developed. HPDP 2 was designed to provide care and support for OVCs and their caregivers by strengthening the capacity of the households, community and system support to meet the needs of OVCs in Osun State, Nigeria. Therefore, this article presents achievements and implications of care and support programme for OVC in Osun State, Nigeria.

\section{Methods}

\subsection{Study Area}

Osun State, created in 1991, is an inland state in south-western Nigeria and with a projected population of 4,332,135 by the year 2015 [11] (Figure 1). The capital 
city is Osogbo. Politically, the State is divided into three Senatorial Districts and 30 Local Government Areas (LGAs). About 19 of the 30 LGAs in Osun State are non-urban local government councils, accounting for $60 \%$ of the 1991 population [12]. About 55\% of the population live in rural areas [11].

The major ethnic group in Osun State is Yoruba, although there are people from other parts of Nigeria in the State. Yoruba and English are the official languages. Economic activities are predominantly commerce and farming. The people of the state are mostly farmers, producing food and cash crops. Transportation in the state is mainly by road. People of Osun State practice Islam, Christianity and Traditional religion.

The Osun State Agency for the Control of AIDS (OSACA), with support from World Bank, coordinates the multisectoral response to HIV/AIDS programme through various technical working groups saddled to facilitate data collection, analysis as well as to provide leadership and direction to all HIV/AIDS programme in the State.

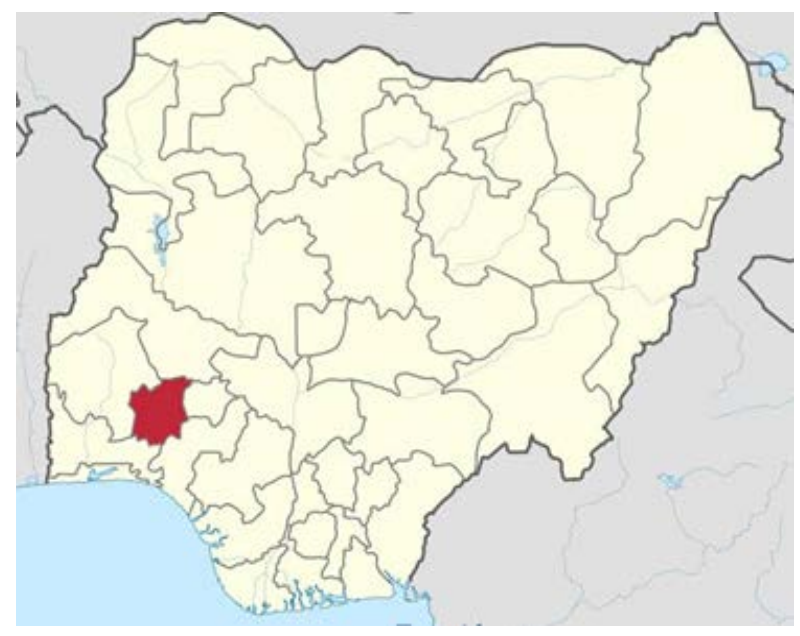

Figure 1. Map of Nigeria showing Osun State.

\subsection{Study Site}

The study sites were the LGAs where the Civil Society Organisations (CSO) working on OVC were based.

\subsection{Target Population}

The target populations for the intervention programme are OVC and their caregivers in eight LGAs of Osun State. Participants who are paternal orphan, maternal orphan, double orphans and vulnerable ones whose parents are alive but infected with or affected by HIV infection were included in this project.

\subsection{Study Design}

A cross-sectional study design was conducted which employed mixed methods with quantitative and qualitative components. This was a five year intervention 
project implemented between the year 2012 and 2016. Eight CSOs were engaged by OSACA under the HIV Programme Development Project (HPDP) in the first and second phases to provide care and support services for OVC in the State. Quantitative method was by analysis of secondary data of the HPDP2 collected by the Civil Society Organizations (CSOs) using several reporting tools (summary forms and registers) and entered into District Health Information System 2 (DHIS2) platform templates designed by the programme implementers.

We obtained qualitative data using Key informant interviews conducted among different CSOs, caregivers and OVC groups. The moderator, note taker and observer for the interview sessions were the researchers. The interview sessions were held among different participants accordingly -8 representatives of CSOs, 8 caregivers each selected across the State and 8 OVC selected across the State who were beneficiaries of the programme.

\subsection{Sample Size and Technique}

Data were retrieved from the DHIS2 platform. The intervention was assigned to 8 CSOs, a target of 100 OVC was given to each CSO. However, DHIS platform showed that a total of 12,353 OVC and their caregivers enrolled for this programme from year 2013 and 2015. The participants were selected because they were either OVC or their caregivers. Participants for the Key Informant Interviews (KII) were recruited through a purposive sampling method, based on characteristics of interest as CSO, OVC or their caregivers, availability and ability to provide relevant information on the project. The $8 \mathrm{CSO}$ representatives, 8 OVCs and 8 caregivers were interviewed.

\subsection{Description of the Interventions}

Advocacy visits were made to the communities and health facilities. Some volunteers in the communities were selected as caregivers by the CSOs as the channel for reaching out to the OVC. Home visits were made to the OVC and their parents/caregivers. They were counselled and the OVC received support according to their identified needs. The caregivers were called to a workshop and didactic sessions conducted to educate them on the special needs and care of the OVC. The training spanned a period of 2 weeks in every community selected.

The eligibility criteria for been a caregiver include, having a source of livelihood, having no crime record and been adjudged responsible by their resident communities. Relatives of OVCs were given preference as caregivers due to the existent family ties.

\section{Home-based care}

Counselling and other psychosocial support were provided to OVC by trained volunteers on personal hygiene, lifestyle, disclosure of HIV status and adherence to treatment. Home based visits were most times conducted by the CSOs without prior announcement to the caregivers to assess how well the OVC were doing under their care. This was done at least twice monthly. 


\section{Educational intervention}

Capacity building workshop was organised for OVC, their parents/caregivers and teachers to improve the educational performance of OVC. The importance of education and healthy living were highlighted and emphasized to them. The OVC were encouraged to register in schools and educational materials like books and other writing materials, school bags, school uniforms etc were provided for them. The school fees were paid directly to the schools; however, the eligibility criteria that must be met by these children included school admission letters from government owned/public schools and evidence of school attendance. The child protection committee was also put in place in the schools. All eligible children were catered for as long as the HPDP lasted, children in privately owned institutions were however excluded due to the high cost implications.

\section{Economic strengthening activities}

Economic strengthening activities were carried out by the CSOs by conducting training sessions on income generating activities (IGA) such as entrepreneurial skills in soap making, tie and dyeing of fabric, bead making, manufacturing of disinfectants and basic computer skills at their different localities. The OVC also received training on financial management and they were given grants for initial take-off of their businesses. The OVC were also linked with micro finance and other internal resources. The economic strengthening activities were conducted bi-annually and all OVC who had completed primary education and had interest were eligible for training. However, only those with promising business prospects were given take-off grants.

\section{Nutritional support activities}

Foodstuffs and supplements were given to the caregivers for distribution to the OVC monthly and quarterly in some instances depending on the quantity of foodstuffs available and the feasibility of monthly distribution due to caregivers' distance and convenience. All the OVC were adjudged eligible for nutritional support with preference given to those with malnutrition. Nutritional status as well as growth and development of eligible OVC were monitored by trained volunteers who conducted growth monitoring measurements quarterly.

\section{Linking OVC to health facilities}

The OVC were referred to health care facilities for basic medical care and treatment as required. The caregivers were educated on immunization and nutrition. Immunization of eligible children was ensured and appropriate health records were kept. Health records of the OVC were collected quarterly from the linked health facilities, also the immunization record of under-fives (a component of the growth monitoring card) were collected from the caregivers and assessed. The health care expenses of some enrolled OVC in the health facilities were paid for by the programme.

\section{Other support services provided}

Financial support was given to the OVC to meet their immediate needs. Clothes, shoes and other basic materials were also provided for them. Some OVC were 
assisted with legal support and birth registrations as required. Street children were integrated into existing families and required support services were rendered to them.

\subsection{Data Analysis}

Data on various interventions were collected by the CSO using specifically designed data collection and reporting tools. Data were entered into District Health Information System 2 (DHIS2) platform and exported into Microsoft excel. The variables on the DHIS2 platform were socio-demographic characteristics of the enrolled OVC disaggregated into sex and age groups, enrolment pattern of orphan and vulnerable children over the years (number of OVC enrolled, provided with care, withdrawn and died), care and support services provided to orphans and vulnerable children in Osun State, Nigeria. OVC accessed psychosocial support services, educational services, protection services as well as economic strengthening services and they were provided with nutritional services as well as shelter and care services. Household heads/caregivers were provided with economic support services. The data also indicated the enrolment pattern of OVC living with HIV infection years (number of OVC enrolled, provided with care, withdrawn and died).

The results were analysed using Microsoft Excel by comparing frequencies and percentages. They were presented in tables and charts. Key informant interviews were conducted by the researchers among the selected CSOs, OVC and the caregivers were analysed using thematic analysis. The interviews were conducted by the researchers.

\subsection{Ethical Consideration}

The ethical approval to conduct this project was obtained from the National and the State Ethical Review Committee of the Federal Ministry of Health, Nigeria. Permission was obtained from the leaders of the identified communities and groups where necessary. The criteria for selection of participants and beneficiaries included informed consent, voluntary declaration of participation in the project and the ability to provide relevant information.

\section{Results}

\subsection{Quantitative Data}

The result of analysis of quantitative data from DHIS2 platform is shown in this section.

\section{Socio-demographic characteristics of the enrolled OVC}

A total of 12,353 Orphans and vulnerable children were enrolled into the project (2013-2015). Most (45\%) of the children were between age of 6 to 12 years. Similar proportions of male (49\%) and female (51\%) OVC were enrolled (Table 1).

\section{Enrolment pattern of the OVC in the programme}

There was an increase in the number of enrolled OVC in the programme over 
the years. Of the 12,353 enrolled OVC, $95 \%$ of them were provided with minimum of one care and support service. However, $6(0.05 \%)$ were reported dead and $3(0.03 \%)$ were loss to follow up. A total of 14 enrolled OVC voluntarily withdrew from the programme (Table 2).

\section{Enrolment pattern of the OVC by gender}

Equal proportions of male and female OVC received a minimum of one care and support service (Figure 2).

\section{Care and support services provided to OVC}

The number of OVC accessing psychosocial support services in the year 2013 was $280(2.8 \%)$, this rose to 3857 (39.1\%) in year 2014 and 5724 (58.1\%) in year 2015. About 5383 OVC were provided with nutritional support and $64.4 \%$ of them were supported in 2015. A total of 5317 children accessed educational services, 1961 were provided with shelter and care services while 1905 accessed healthcare services. While protection service was not accessed in year 2013, about $22.3 \%$ and $77.7 \%$ of the OVC accessed this service in 2014 and 2015 respectively. A total of 503 OVC received economic strengthening services while 270 household heads were provided with economic support through this programme (Table 3).

\section{Overall care and support services provided}

Of all the services rendered to OVC, provision of psychosocial support was ranked highest (79.8\%). This was followed by provision of nutritional services (43.5\%), provision of educational support (43\%), provision of shelter (15.8\%), protection services $(4.7 \%)$, healthcare services $(15.4 \%)$, economic strengthening services to the children (4.1\%) and economic support to the household heads (2.2\%) (Figure 3 ).

Table 1. Socio-demographic characteristics of the enrolled orphans and vulnerable children in care and support programme.

\begin{tabular}{|c|c|c|c|c|c|c|c|c|}
\hline \multirow{3}{*}{ Variable } & \multicolumn{6}{|c|}{ Years } & \multirow{2}{*}{\multicolumn{2}{|c|}{$\begin{array}{c}\text { Total } \\
\mathrm{n}=12,353\end{array}$}} \\
\hline & \multicolumn{2}{|c|}{$\begin{array}{c}2013 \\
n=300\end{array}$} & \multicolumn{2}{|c|}{$\begin{array}{c}2014 \\
n=4288\end{array}$} & \multicolumn{2}{|c|}{$\begin{array}{c}2015 \\
\mathrm{n}=7765\end{array}$} & & \\
\hline & $\mathrm{n}$ & $\%$ & $\mathrm{n}$ & $\%$ & $\mathrm{n}$ & $\%$ & $\mathrm{n}$ & $\%$ \\
\hline \multicolumn{9}{|c|}{$\begin{array}{l}\text { Age ( in years, } \\
\text { as presented in DHIS) }\end{array}$} \\
\hline $0-5$ & 69 & 23.00 & 590 & 13.76 & 804 & 10.35 & 1463 & 11.84 \\
\hline $6-12$ & 140 & 46.67 & 1924 & 44.87 & 3552 & 45.75 & 5616 & 45.46 \\
\hline $13-17$ & 91 & 30.33 & 1774 & 41.37 & 3409 & 43.90 & 5274 & 42.70 \\
\hline \multicolumn{9}{|l|}{ Sex } \\
\hline Male & 142 & 47.33 & 2143 & 49.98 & 3735 & 48.10 & 6020 & 48.73 \\
\hline Female & 158 & 52.67 & 2145 & 50.02 & 4030 & 51.90 & 6333 & 51.27 \\
\hline
\end{tabular}


Table 2. Enrolment pattern of orphan and vulnerable children in care and support programme.

\begin{tabular}{|c|c|c|c|c|c|c|c|}
\hline \multirow{3}{*}{ Variables } & \multicolumn{6}{|c|}{ Years } & \multirow{3}{*}{ Total } \\
\hline & \multicolumn{2}{|c|}{2013} & \multicolumn{2}{|c|}{2014} & \multicolumn{2}{|c|}{2015} & \\
\hline & $\mathrm{n}$ & $\%$ & $\mathrm{n}$ & $\%$ & $\mathrm{n}$ & $\%$ & \\
\hline Number of enrolled OVC & 300 & 2.43 & 4288 & 34.71 & 7765 & 62.86 & 12,353 \\
\hline $\begin{array}{l}\text { OVC provided with minimum } \\
\text { of one care and support service }\end{array}$ & 300 & 2.57 & 4210 & 36.03 & 7173 & 61.40 & 11,683 \\
\hline $\begin{array}{l}\text { OVC who voluntarily withdrawn } \\
\text { from the programme }\end{array}$ & 0 & 0.00 & 9 & 64.29 & 5 & 35.71 & 14 \\
\hline OVC who were lost to follow-up & 0 & 0.00 & 0 & 0.00 & 3 & 100.00 & 3 \\
\hline OVC known to have died & 0 & 0.00 & 0 & 0.00 & 6 & 100.00 & 6 \\
\hline
\end{tabular}

Table 3. Care and support services provided to orphans and vulnerable children in Osun State, Nigeria.

\begin{tabular}{|c|c|c|c|c|c|c|c|}
\hline \multirow{3}{*}{ Care and support services } & \multicolumn{6}{|c|}{ Years } & \multirow{3}{*}{ Total } \\
\hline & \multicolumn{2}{|c|}{2013} & \multicolumn{2}{|c|}{2014} & \multicolumn{2}{|c|}{2015} & \\
\hline & $\mathrm{n}$ & $\%$ & $\mathrm{n}$ & $\%$ & $\mathrm{n}$ & $\%$ & \\
\hline $\begin{array}{l}\text { OVC accessing psychosocial } \\
\text { support services }\end{array}$ & 280 & 2.84 & 3857 & 39.11 & 5724 & 58.05 & 9861 \\
\hline $\begin{array}{l}\text { OVC provided with } \\
\text { nutritional services }\end{array}$ & 80 & 1.49 & 1838 & 34.14 & 3465 & 64.37 & 5383 \\
\hline $\begin{array}{l}\text { OVC accessing } \\
\text { educational services }\end{array}$ & 180 & 3.38 & 1797 & 33.80 & 3340 & 62.82 & 5317 \\
\hline $\begin{array}{l}\text { OVC provided with shelter } \\
\text { and care services }\end{array}$ & 0 & 0.00 & 720 & 36.72 & 1241 & 63.28 & 1961 \\
\hline $\begin{array}{l}\text { OVC accessing } \\
\text { healthcare services }\end{array}$ & 80 & 4.20 & 721 & 37.85 & 1104 & 57.95 & 1905 \\
\hline $\begin{array}{l}\text { OVC accessing } \\
\text { protection services }\end{array}$ & 0 & 0.00 & 130 & 22.26 & 454 & 77.74 & 584 \\
\hline $\begin{array}{l}\text { OVC accessing economic } \\
\text { strengthening services }\end{array}$ & 20 & 3.98 & 105 & 20.87 & 378 & 75.15 & 503 \\
\hline $\begin{array}{l}\text { Household heads provided } \\
\text { with economic support }\end{array}$ & 20 & 7.41 & 215 & 79.63 & 35 & 12.96 & 270 \\
\hline
\end{tabular}

Care and support services provided to OVC living with HIV infection in Osun State, Nigeria

Enrolment pattern of OVC living with HIV infection in care and support programme is shown on Table 4. There was an increase in the number of enrolled client in the programme over the years. A total of 1033 of the enrolled OVC living with HIV infection were provided with minimum of one care and support service. About 645 clients received adherence support services, however, 14 clients voluntarily withdrew from the programme and 3 clients were lost to follow up. None of the enrolled OVC living with HIV infection died during this programme (Table 4). 


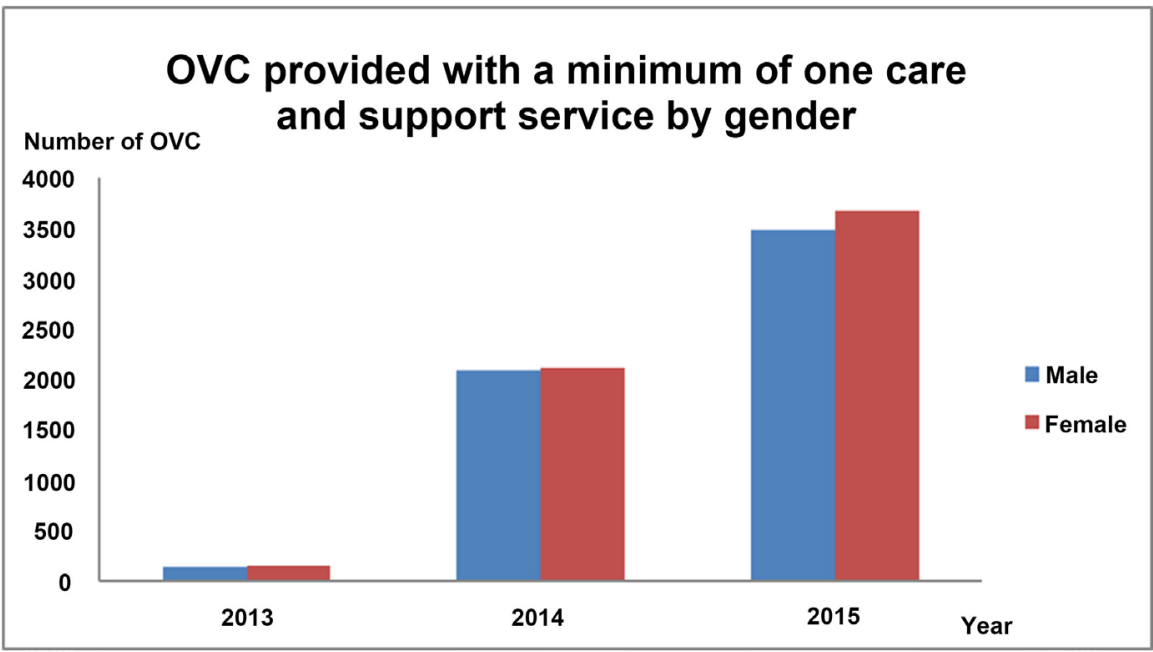

Figure 2. Orphans and vulnerable children provided with at least one care and support services by gender.

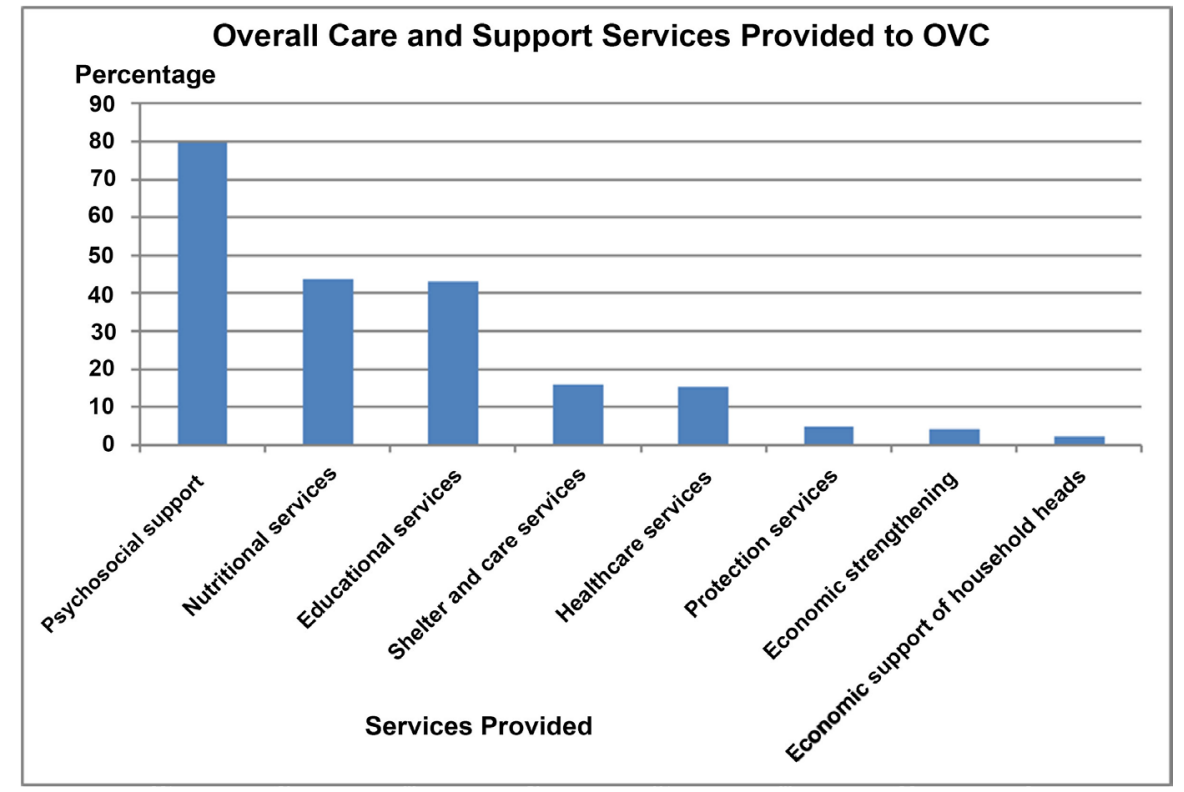

Figure 3. Overall care and support services provided to OVC in Osun State, Nigeria.

\subsection{Qualitative Study}

\section{Description of CSO in terms of location and services provided}

The location and services provided by the CSO are summarised in Table 5 .

Emerging themes from the thematic analysis

The major themes from the thematic network analysis of the qualitative data obtained from separate KII conducted among the among the CSO, caregivers and OVC highlighted the achievements, strength, weaknesses, significant contributions and challenges of the HPDP in Osun State.

The achievements of the HPDP in care and support of OVC as discussed by the CSO revealed the services offered to the OVC (Table 5). Each of the eight (8) CSOs working on the OVC was given a target to support $100 \mathrm{OVC}$ for the 
Table 4. Enrolment pattern of OVC living with HIV infection in care and support programme.

\begin{tabular}{|c|c|c|c|c|c|c|c|}
\hline \multirow{3}{*}{ Variables } & \multicolumn{6}{|c|}{ Years } & \multirow{3}{*}{ Tota } \\
\hline & \multicolumn{2}{|c|}{2013} & \multicolumn{2}{|c|}{2014} & \multicolumn{2}{|c|}{2015} & \\
\hline & $\mathrm{n}$ & $\%$ & $\mathrm{n}$ & $\%$ & $\mathrm{n}$ & $\%$ & \\
\hline Number of clients enrolled & 1 & 0.05 & 387 & 20.74 & 1478 & 79.21 & 1866 \\
\hline $\begin{array}{l}\text { Number of clients provided with a } \\
\text { minimum of one care service }\end{array}$ & 1 & 0.10 & 290 & 28.07 & 742 & 71.83 & 1033 \\
\hline $\begin{array}{l}\text { Number of clients provided with } \\
\text { prevention with positive service }\end{array}$ & 1 & 0.14 & 199 & 29.10 & 484 & 70.76 & 684 \\
\hline $\begin{array}{l}\text { Number of clients provided with } \\
\text { adherence support service }\end{array}$ & 1 & 0.15 & 105 & 16.28 & 539 & 83.57 & 645 \\
\hline $\begin{array}{l}\text { Number of non-ART clients provided } \\
\text { with support services }\end{array}$ & 0 & 0.00 & 97 & 55.11 & 79 & 44.89 & 176 \\
\hline $\begin{array}{l}\text { Number of clients that voluntarily } \\
\text { withdrew from service }\end{array}$ & 0 & 0.00 & 2 & 11.11 & 16 & 88.89 & 18 \\
\hline Number of client lost to follow up & 0 & 0.00 & 2 & 66.67 & 1 & 33.33 & 3 \\
\hline Number of client who died & 0 & 0.00 & 0 & 0.00 & 0 & 00.00 & 0 \\
\hline
\end{tabular}

Table 5. Civil society organisations/community based organisations in respective local government areas, care and support services provided and the number of children supported.

\begin{tabular}{|c|c|c|c|c|c|}
\hline $\mathrm{S} / \mathrm{N}$ & $\begin{array}{l}\text { Local Government } \\
\text { Area (LGA) }\end{array}$ & $\begin{array}{l}\text { Civil Society Organisation/ } \\
\text { Community Based } \\
\text { Organisation }\end{array}$ & Care and support services provided & Target & $\begin{array}{l}\text { Number of } \\
\text { children } \\
\text { supported }\end{array}$ \\
\hline 1 & $\begin{array}{l}\text { Irewole LGA } \\
\text { Osogbo LGA }\end{array}$ & $\begin{array}{l}\text { Blessing of God Support } \\
\text { Group }\end{array}$ & $\begin{array}{l}\text { Educational services, psychosocial support, Nutritional } \\
\text { support, Shelter, protection services, healthcare support } \\
\text { and economic strengthening activities }\end{array}$ & 100 & 255 \\
\hline 2 & $\begin{array}{l}\text { Olorunda LGA } \\
\text { Egbedore LGA } \\
\text { Ede North LGA }\end{array}$ & $\begin{array}{l}\text { Hope for Tomorrow } \\
\text { Children and Women } \\
\text { Initiative }\end{array}$ & $\begin{array}{l}\text { Educational services, psychosocial support, protection } \\
\text { services, healthcare support, Nutritional support, Shelter } \\
\text { and economic strengthening activities }\end{array}$ & 100 & 145 \\
\hline 3 & $\begin{array}{l}\text { Isokan LGA } \\
\text { Ejigbo LGA }\end{array}$ & $\begin{array}{l}\text { Organization for Concerned } \\
\text { Souls International }\end{array}$ & $\begin{array}{l}\text { Educational services, psychosocial support, protection } \\
\text { services, healthcare support, legal aids and economic } \\
\text { strengthening activities }\end{array}$ & 100 & 118 \\
\hline 4 & $\begin{array}{c}\text { Iwo LGA } \\
\text { Osogbo LGA }\end{array}$ & $\begin{array}{l}\text { Eminent Charitable and } \\
\text { Humanitarian Foundation } \\
\text { (ECHF) }\end{array}$ & $\begin{array}{l}\text { Educational services, psychosocial support, Nutritional } \\
\text { support, Shelter, protection services, healthcare support } \\
\text { and economic strengthening activities }\end{array}$ & 100 & 243 \\
\hline 5 & $\begin{array}{l}\text { Obokun LGA } \\
\text { Ife South LGA } \\
\text { Ife North LGA }\end{array}$ & $\begin{array}{l}\text { Women and Development } \\
\text { Movement (WADEM) }\end{array}$ & $\begin{array}{l}\text { Protection services, healthcare support, educational } \\
\text { services, psychosocial support, Nutritional support, } \\
\text { economic strengthening activities }\end{array}$ & 100 & 178 \\
\hline 6 & $\begin{array}{c}\text { Ilesa west LGA Ife } \\
\text { East LGA } \\
\text { Orolu LGA }\end{array}$ & $\begin{array}{l}\text { Methodist Care \& } \\
\text { Development Trust } \\
\quad \text { (Metcare) }\end{array}$ & $\begin{array}{l}\text { Educational services, psychosocial support, Nutritional } \\
\text { support, Shelter, economic strengthening activities }\end{array}$ & 100 & 206 \\
\hline 7 & $\begin{array}{l}\text { Ilesha West LGA } \\
\text { Ayedaade LGA } \\
\text { Irewole LGA }\end{array}$ & $\begin{array}{l}\text { Life Repairers International } \\
\text { Ministry (LIRM) }\end{array}$ & $\begin{array}{l}\text { Educational services, psychosocial support, Nutritional } \\
\text { support, Shelter, economic strengthening activities }\end{array}$ & 100 & 198 \\
\hline 8 & $\begin{array}{l}\text { Ede North LGA } \\
\text { Boluwaduro LGA } \\
\quad \text { Ila LGA }\end{array}$ & $\begin{array}{l}\text { Assist Women \& Develop } \\
\text { Children Initiative } \\
\text { (AWODECI) }\end{array}$ & $\begin{array}{l}\text { Educational services, psychosocial support, Nutritional } \\
\text { support, Shelter, protection services, healthcare support, } \\
\text { legal aids and economic strengthening activities }\end{array}$ & 100 & 238 \\
\hline
\end{tabular}


HPDP programme, although all the CSOs exceeded the target given to them. One of the CSOs represented said:

The services we rendered were enormous, where do I start from, we provided psychosocial support mainly by conducting regular home visits, we provided for the heads of different household by strengthening them economically and we trained these children through school (CSO5).

Another respondent added that ".... that is not all; we paid rents for so many so that they could have roofs over their heads"(CSO1).

According to the caregivers and OVC that benefitted from the services, the services they accessed from the programme include home visits, shelter, educational support, free education, educational materials, psychosocial support, counselling, spiritual support, material support (school uniform, clothing, shoes, etc.), provision of school fees, income generation or microfinance, nutritional support, life skills education, HIV/AIDs information and awareness, healthcare services, protection and legal services. Excerpts from the interview sessions among the OVC are as follows:

I am able to speak to use in English language because of the programme, the cloth I am wearing, the way I look, I owe it to the programme. I had lost hope and they restored it (Orphan 4, male, 25 years).

My being is school is because of the programme, I am now a university student due to the support from the programme (Orphan 1, male, 23 years).

Eating three square meals was difficult before the intervention of the HPDP, all thanks to them for providing and encouraging my caregivers (Orphan 8, female, 15 years).

The caregivers in their interview sessions listed the achievement of the programme to include enrolment of the OVC into care, building the capacity of caregivers and financial support from the programme.

Excerpts from the interview sessions among the caregivers are as follows:

The key achievement of the programme was that we were able to identify these neglected children and enrolled them into care, we have removed a lot of vulnerable children who would have become beggars from the street and settled them in homes. This goes a long way in securing the future for our children and nation at large and I am honoured to be part of it (Caregiver 3, female, 47 years).

I have learnt on how to take care of the specific needs of the orphans through several training sessions, especially skills in proper counselling and care for orphans (caregiver 7, male, 39 years).

The strengths of the HPDP in care and support of OVC include acceptability of the programme as the economic strengthening services provided to the OVC were widely accepted by the members of the community. Interviews among the caregivers and OVC revealed that the project was well executed, properly organised and very impactful in transforming the lives of the OVC, one of the caregivers said that "the programme was well designed to alleviate the sufferings of the vulnerable group, the support we got was commendable, and the OVC 
had a sense of belonging while the programme lasted" (Caregiver 1, female, 40 years).

Educational services and economic strengthening was the most impactful service rendered during the programme as pointed out by majority of the OVC involved in the programme. As expressed by one of the OVC.

The project helped me through my West African School Certificate Examinations, I am grateful for this because I had already given up on education since my parents died, and my uncle had stroke, I wanted to engage in street hawking of sachet water to meet my immediate needs, I am grateful (OVC 2, female, 16 years).

The weaknesses of the HPDP in care and support of OVC include inadequate resources as the CSOs complained that a little fraction of the OVC in the State was reached. It was also reiterated that the OVC were neglected in the HPDP2 "extension" which was the second part of the programme. A participant expressed his concern as this:

Although some children were willing to benefit and leave the streets, there is a little target for the organisation, funds were made available for the targeted number of $100 \mathrm{OVC}$, and hence the funds became inadequate to provide the necessary services as intended (CSO6).

Majority of the CSOs were also concerned about the lack of a continuity plan as expressed by one of them that "When the project ended, there was no agency of the government that was ready to take up the good initiative provided by HPDP" (CSO4).

The challenges of the HPDP in care and support of OVC that were pointed out by the CSOs were the lack of a sustainability plan, irregular funding and support which created some stop-gaps in-between the programme. According to them, this caused the reversal the earlier gains. Upon completion of the programme however, there was an extension of the programme over a 6 months period based on the availability of funds, however, some CSOs were no longer included in the HPDP2 extension. CSOs that were able to submit requested reports and attend relevant meetings were included in the HPDP extension by the implementers. Interviews conducted among the OVC and their caregivers showed similar findings. One of the caregivers said that "I don't know what will become of the Orphans now as they were left out of the HPDP extension upon completion of the programme about 6 months ago" (Caregiver2, female, 38 years).

The challenges identified were same as pointed out during the KII, they included lack of adequate funding and the absence of a continuity plan, also the caregivers pointed out some OVC were left out of the programme, inadequate capturing of the OVC data in their communities prior to commencement of the programme as a baseline survey was not conducted. Some OVCs withdrew from this programme. Although some CSOs were informed that some OVCs and their caregivers relocated to other States, reasons for the withdrawal were not disclosed to the CSOs. 
Another challenge mentioned by the caregivers is the process of integrating the OVC into their homes especially where the caregivers were not related to the OVC. It requires a lot of counselling and reassurance.

Some OVC in their interview sessions highlighted maltreatment by some caregivers in terms of provision of some needs and child labour, an assertion debunked by caregivers interviewed.

The significant contributions of HPDP in care and support of OVC as agreed by the participants include economic strengthening, income generating activities and skills. An orphan said that "the proceeds from the soap making that I learnt from the programme is enough to take me through the day, I can now afford a 3 square-meal" (OVC2, female, 16 years).

The enrolled orphans and vulnerable children attained great educational milestones since HPDP commenced. A caregiver quickly pointed out that "one OVC has just been admitted into the university, with the help of the educational support provided by this programme"(Caregiver 1, female, 40 years).

\section{Discussion}

The increased trend in the number of OVC recruited into the programme yearly is similar with the findings of a study among the OVC in Kogi State, Nigeria [13], however there was a huge disparity in the number of enrolled OVC uploaded on the DHIS 2 platform and the number of OVC supported by the CSOs from their response during the interview. Most of the enrolled children were provided with minimum of one care and support service. Almost all the children seen were provided with psychosocial support; this is not unexpected as HIV/AIDS, which was the major cause of death of one or both parent(s) of these children, is associated with a lot of stigma, fear and psychological stress. It has been established that psychosocial support helps children and young people cope with emotional trauma and stress [14].

Being orphaned or made vulnerable due to the death or acute illness of one or both parent(s) plays a role in the child's school attendance. In general, OVC have lower rates of enrolment, attendance, and school performance than non-orphaned and less vulnerable children [15] [16] [17]. In Africa, secondary schools are rarely free [16] and the OVC constitute the majority of those who are absent from and drop out of schools even if they begin school [18] [19] while half of the children enrolled at the end of primary school do not continue to the secondary level [20]. In addition, OVC are poor in their academic performance due to lack of basic needs and adequate time to study as majority of them work for their survival, needs or to supplement their families/relative meagre income [21]. A large proportion of the children accessed educational services from HPDP in Osun State of Nigeria. In addition to building their self-esteem and confidence, educational support is very important for the OVC to become literate and to be well integrated into the society. Apart from impacting knowledge, education also helps in the psychosocial development of these children as they mingle with other kids in school. Most of the CSOs and caregivers involved in the HPDP project ac- 
knowledge the improvement of the educational access of the OVC as one of the significant achievements relative to other services provided. As part of the achievements mentioned during the interview, a CSO boasted of helping a child to the university level through the fund provided by HPDP.

Results from the HPDP showed that similar proportions of boys and girls accessed educational and other support services. The project offered equal opportunities for girls and boys: evidence from earlier studies showed that promoting girls education, not only helps in educational outcomes but also helps in achieving an AIDS-free generation [22]. Some studies have shown that education can affect infection rates, as more highly educated girls and young women are more likely to be able to negotiate safer sex and reduce HIV rates [23].

Almost half of the total population of OVC in Osun State, Nigeria were provided with nutritional support and health services. Malnutrition is a major problem, with dreadful complications and eventually death among children less than 5 years of age [24]. The association between HIV/AIDS and nutrition confers particular importance to the impact that balanced diet has on the prognosis of the infection, coupled with the fact that adequate nutrition helps in physical growth and development [25]. However, all the services provided are important and are interwoven, because there is a positive link between education, nutrition and prevention of infection [3].

Home visits were made to the OVC in this programme even though the frequency of visits was not recorded. Home visit has been shown to be very helpful in care and support programmes for OVC. Several evaluations have pointed out that home visiting programmes have a positive impact on the OVC when volunteers regularly visit the households and spend adequate time with the children, especially those at high risk for poor health outcomes who do not present at health centres [26]. As found in other State in Nigeria, the HPDP for OVC in Osun State provides several opportunities to improve access to health care services through prompt referral and appropriate linkage of the OVC to health facilities [13].

The HIV/AIDS epidemic has impoverished communities to the point where many children are left without suitable shelter or care. Shelter is a basic need, thus over a thousand OVC were provided with shelter during this programme. Provision of shelter will take the OVC off the streets where they are exposed to different levels of danger and social vices. Orphans and vulnerable girls constitute the majority of those girls who are sexually abused at early age [22]. When children live without adequate shelter and caregiver, they become highly vulnerable to abuse and they have stunted development [27]. Caregivers were assigned to OVC in Osun State to provide necessary supervision and access to services.

The OVC accessing economic strengthening services have increased in Osun State over the years and the programme has provided these children with opportunities for vocational training that enabled them engage in gainful activities. However, findings from qualitative studies revealed that these supports and assistance were inconsistent and inadequate. 
The core values of care and support programmes for OVC are rooted in the principles of child protection and development and it ensures that programmes that place the best interests of the child and his or her family above all are implemented [3]. Thus, the HPDP in Osun State made efforts to provide legal aids for the OVC to confront and minimize associated legal problem which include stigma, social neglect, abuse and exploitation, including trafficking, issues with inherited properties and land tenure.

The number of HIV positive children covered by the programme grew over time due to increased programme awareness, intensification of community mobilization efforts and combating stigmatization against them. In addition, HIV status was not a criterion for enrolment as enrolled OVC included children whose HIV statuses were identified after HIV counselling and testing.

The limitations that must be taken into consideration from this project include the discrepancies in the data from DHIS2 platform and the qualitative findings from the discussion with the CSOs. Secondly, the data reporting tool for DHIS platform is devoid of some variables of interest that could have been used for further analysis. The researchers relied on the service providers as the source of data used, also the DHIS2 data lacked information on interventions categories disaggregated into various levels of support provided. Despite these limitations, this report provided information on the achievements of the HPDP programme among OVC in Osun State, Nigeria and identified the challenges of the project.

\section{Implications for Programming}

A large number of OVC had been integrated into the society through HPDP, securing a better life and future for these children. All the services should be integrated so as to prevent duplication of programmes, for instance provision of healthcare services, psychosocial and nutritional services should all be rendered together and concurrently in the same community, by the same organisation and even on the same set of children as the support is required.

Reaching out to the HIV positive children being a "Hard to reach population" was made possible due to the term "vulnerable children" used to address all children including those HIV positive hence eliminating stigmatization, furthermore to avoid stigmatization, the status of the children was not used as a basis for recruitment.

A better and more realistic target, that will ensure a greater number of OVC are helped, should be given to the CSOs. There should be a feasible plan and adequate funding for monitoring and evaluation process for more detailed reporting. There should therefore be a "minimum prevention package of services" when dealing with OVCs as their needs are numerous. A situation analysis should be done and linkages can be made throughout a system of care to cover the range of needs identified through household assessment.

\section{Conclusion}

Programme for children orphaned and made vulnerable by HIV/AIDS will con- 
tribute to the achievement of HIV/AIDS prevention, care and support programme to build HIV/AIDS free generation by responding to the physical, social and mental needs of these children and their families in their communities. The achievements of the programme in ensuring better care for the orphans and vulnerable children were enormous and there is a need to scale-up this programme while the gains of the programme need to be sustained through ownership by the community and the government at all levels.

\section{Recommendations}

A continuity plan should be put in place to avoid reversal of gains and achievements of the HPDP. Furthermore, subsequent scaling up of the programme will ensure more OVC are reached, therefore an upward review of the target and funds given to the stakeholders in the programme is recommended.

Donors and implementer must support the collection of sound empirical evidence. Evidence based approach is advocated for further programmes, for this to be possible, proper monitoring and evaluation is necessary, therefore, more efficient data collection tools need to be designed and previous ones reviewed with training and retraining of staff on the use of the reporting tools. Community ownership and integration of the programmes into existing programmes for orphans and vulnerable children in the State should be ensured.

\section{Acknowledgements}

The evaluation team acknowledges the World Bank and OSACA for funding the evaluation and dissemination of the result of this project. We would also like to acknowledge the CSOs, caregivers and the selected OVC for their cooperation during the interviews.

\section{Funding}

Data analysis and publication of this article was supported by HIV/AIDS Fund (HAF) from World Bank through Osun State for the Control of AIDS (OSACA). The content of this article is the responsibility of the authors and does not necessarily reflect the views, analysis or policies of World Bank.

\section{Conflicts of Interest}

The authors declare no conflicts of interest regarding the publication of this paper.

\section{References}

[1] World Bank (2005) The OVC Toolkit for SSA-A Toolkit on How to Support Orphans and Other Vulnerable Children (OVC) in Sub-Saharan Africa (SSA)-World Bank Africa Region and World Bank Institute.

[2] UNAIDS, UNICEF, USAID (2004) Children on the Brink 2004-A Joint Report of New Orphan Estimates and a Framework for Action. USAID, Geneva. http://www.unicef.org/publications/cob_layout6-013.pdf 
[3] The President's Emergency Plan for AIDS Relief (2006) Orphans and Other Vulnerable Children Programming Guidance for United States Government In-Country Staff and Implementing Partners.

[4] UNICEF (2013) Towards an AIDS-Free Generation Children and AIDS: Sixth Stocktaking Report 2013. http://www.unicef.org/publications/index_70986.html

[5] AVERT (2017) Key Affected Populations: Children and HIV/AIDS. http://www.avert.org/children-orphaned-hiv-and-aids.htm

[6] Tagurum, Y.O., Chirdan, O.O., Bello, D.A., Afolaranmi, T.O., Hassan, Z.I., Iyaji, A.U. and Idoko, L. (2015) Situational Analysis of Orphans and Vulnerable Children in Urban and Rural Communities of Plateau State. Annals of African Medicine, 14, 18-24. http://www.annalsafrmed.org/text.asp?2015/14/1/18/148714 https://doi.org/10.4103/1596-3519.148714

[7] Marsden, P. and Guyer-Miller, L. (2011) Social Welfare Workforce Strengthening for Orphans and Vulnerable Children (OVC) Care, Support and Protection in Nigeria. Capacity plus Scoping Visit Report, Nigeria.

[8] Berry, L. and Guthrie, T. (2003) Rapid Assessment: The Situation of Children in South Africa. The University of Cape Town Children Institute-Save the Children, Cape Town.

[9] Bhargava, A. and Bigombe, B. (2003) Public Policies and the Orphans of AIDS in Africa. BMJ, 326, 1387. https://doi.org/10.1136/bmj.326.7403.1387

[10] Foster, G. and Williamson, J. (2000) A Review of Current Literature of the Impact of HIV/AIDS on Children in Sub-Saharan Africa. AIDS, 14, S275-S284.

[11] National Population Commission (2006) Final Results of 2006 Population Census of Nigeria.

[12] Osun State Agency for the Control of AIDS (2016) Osun State Civil Society Organization (CSO) Directory. Osogbo, Osun State.

[13] Adelekan, A.L., Musa, G., Anyebe, G., Rosemary, F., Muraina, I., Ameloko, E., et al. (2017) Achievements and Implications of Care and Support Programme among Orphaned and Vulnerable Children: A Systematic Evaluation of HAF II Project in Kogi State, Nigeria. IOSR Journal of Nursing and Health Science, 6, 39-44. https://doi.org/10.9790/1959-0601023944

[14] Nugent, A. and Masuku, Z. (2007) Psychosocial Support for Orphans and Vulnerable Children-An Introduction for Outreach Workers. World Education and John Snow, Inc., Boston, 28 p.

[15] Bennell, P., Hyde, K. and Swainson, N. (2002) The Impact of the HIV/AIDS Epidemic on the Education Sector in Sub-Saharan Africa: A Synthesis of the Findings and Recommendations of Three Country Studies. Centre for International Education, University of Sussex Institute of Education, Brighton.

[16] Evans, D. and Miguel, E. (2007) Orphans and Schooling in Africa: A Longitudinal Analysis. Demography, 44, 35-57. https://doi.org/10.1353/dem.2007.0002

[17] Tu, X., Lv, Y., Li, X., Fang, X., Zhao, G., Lin, X., Hong, Y., Zhag, L. and Stanton, B. (2009) School Performance and School Behavior of Children Affected by AIDS in China. Vulnerable Children and Youth Studies, 4, 199-209. https://doi.org/10.1080/17450120902814420

[18] Case, A., Paxson, C. and Ableidinger, J. (2004) Orphans in Africa: Parental Death, Poverty, and School Enrollment. Demography, 41, 483-508. https://doi.org/10.1353/dem.2004.0019

[19] Monasch, R. and Boerma, J. (2004) Orphanhood and Childcare Patterns in Sub-Saharan 
Africa: An Analysis of National Surveys from 40 Countries. AIDS, 18, 55-65. https://doi.org/10.1097/00002030-200406002-00007

[20] Bryant, M., Bread, J., Sabin, L., Brooks, M.I., Scott, N., Larson, B.A., Biemba, G., et al. (2012) PEPFAR's Support for Orphans and Vulnerable Children: Some Beneficial Effects, But Too Little Data and Programs Spread Thin. Health Affairs, 31, 1508-1518. https://doi.org/10.1377/hlthaff.2012.0230

[21] Mwoma, T. and Pillay, J. (2016) Educational Support for Orphans and Vulnerable Children in Primary Schools: Challenges and Interventions. Issues in Educational Research, 26, 82-97. http://www.iier.org.au/iier26/mwoma.html

[22] UNICEF (2004) Girls, HIV/AIDS and Education. The United Nations Children's Fund (UNICEF), New York, 1-27. http://www.unicef.org/girlseducation/index.html

[23] Hargreaves, J. and Boler, T. (2006) Girl Power: The Impact of Girls' Education on HIV and Sexual Behavior.

[24] Rice, A.L., Sacco, L., Hyder, A. and Black, R.E. (2000) Malnutrition as an Underlying Cause of Childhood Deaths Associated with Infectious Diseases in Developing Countries. Bulletin of the World Health Organization, 78, 1207-1221.

[25] Highleyman, L. (2006) Nutrition and HIV. BETA, 18, 18-32.

[26] Sherr, L. and Doll, M. (2011) PEPFAR OVC Evaluation: How Good at Doing Good? PEFPAR through USAID by Global Health Technical Assistance Project.

[27] Foster, G. (2000) The Capacity of the Extended Safety Net for Orphans in Africa. Psychology, Health \& Medicine, 5, 55-63. https://doi.org/10.1080/135485000106007 